\title{
An integrated continuous improvement model of TPM, TPS and TQM for boosting profitability of manufacturing industries: An innovative model \& guideline
}

\author{
Haftu Hailu ${ }^{a^{*}}$, Solomon Mengstu ${ }^{b}$ and Tewedros Hailu ${ }^{c}$
}

${ }^{a}$ Director, Public Service \& Human Resource Development Ministry, Ethiopia Kaizen Institute, Addis Ababa, Ethiopia

${ }^{b}$ Assisstant Professor, Debre Birhan University, Industrial Engineering Department, Debre Birhan, Amhara, Ethiopia ${ }^{c}$ Lecturer, Axsum University, Mechanical Engineering Department, Axum, Tigray, Ethiopia

\section{H R O N I C L E}

Article history:

Received: September 2, 2017

Received in revised format: September 26, 2017

Accepted: November 5, 2017

Available online:

November 5, 2017

\section{Keywords:}

Continuous Improvement

Total Productive Maintenance

Toyota Production System

Total Quality Management

PDCA

\section{A B S T R A C T}

The purpose of this research is to develop an integrated literature based TPM, TPS and TQM model through PDCA cycle, and implementation guideline for the implementation of the model. At this time very few studies are available on this research area, even this research on integrated model of TPM, TPS and TQM practices, and implementation guideline are not corresponding. The methodology to develop the model and the implementation guideline is based on identifying the uniqueness and common practices of TPM, TPS and TQM systems, existing practice of the integration and implementation guideline, identifying the existing gaps on the model and implementation guideline, developing new integrated TPM, TPS and TQM practice model, and implementation guideline. Previous very few studies of uniqueness, common practices and implementation guideline of the three systems are preserved. The findings of this research, an integrated cutting-edge model of TPM, TPS and TQM practices and implementation guidelines are developed. The originality / value of the developed model and implementation guideline enable manufacturing industries continuously to be competitive and profitable.

\section{Introduction}

Continuous Improvement is a very critical in the manufacturing industries today to enhance customer satisfaction, to become the cost leader and also to remain competitive in the global world today. The implementation of continuous improvement approach involves the use of a number of tools and techniques to identify problems, wastes, and process variations and to improve the manufacturing processes in order to achieve organizational excellence (Tesfayea \& Kitaw, 2017). Continuous improvement is one of the tactics that companies should adapt to survive in dynamic environment (Getachew et al., 2017). Continuous improvement is a very critical tool in the manufacturing industries today to enhance customer satisfaction, to become the cost leader and also to remain competitive in the global world today (Jaafreh et al., 2012). Since the 1980s there has been an increasing awareness and implementation of world class practices associated with Total Productive Maintenance (TPM), Just in Time (JIT) and

* Corresponding author. Tel: +251-912-19-27-41

E-mail address: hhea192741@gmail.com (H. Hailu) 
Total Quality Management (TQM) (Cua et al., 2001). Nevertheless, there has not been a careful examination of the common, unique practices and implementation guideline associated with these programs. This study develops an integrated innovative model of TPM, TPS and TQM practices ( 3T's ) and implementation guideline. The relationships between the use of these practices through PDCA Cycle is examined. 3T's have analogous ultimate goal-line of continuously waste reduction to enhance profitability (Schonberger, 1986; Nakajima, 1988; Ohno, 1988; Powell, 1995). Together the practices of 3T's through PDCA approach form a wide-ranging and reliable set of manufacturing practices leads to profitability. Therefore, manufacturing industries are likely to combine the implementation of 3T's practices. Nevertheless, most of the studies on 3T's investigate these programs separately. Only a few previous studies have tried to explore the relationship between TQM and JIT with case application (Tesfayea \& Kitaw, 2017); JIT and TQM through TOC with implementation plan (Getachew et al., 2017); Roles of TQM and JIT (Dametew et al., 2017); TQM, JIT and TPM (Krishnan \& Parveen, 2013); JIT and TPM (Abdallah \& Matsui, 2007); TQM, and TPS (Andersson et al., 2006); TQM, JIT and TPM (Cua et al.,2001), TQM and JIT empirically (Flynn et al., 1995; Sriparavastu \& Gupta, 1997); TPM with JIT and TQM (McKone et al., 2001); TQM, JIT, and TPM (Roth \& Miller, 1992); JIT, TPM and Quality control and factory automation with worker participation (Huang, 1991); TQM and TPM supports JIT (Imai, 1998); TPM \& TQM (Boateng et al., 2016); Relationship and Comparison between JIT, TPM \& TQM (Paliwal et al., 2013). The conceptual research cited above provides evidence of a renewed interest in the study of manufacturing programs with an emphasis on their simultaneous investigation. While researchers recognize the value of investigating interrelated entities simultaneously, there is no study that provides empirical examination of the joint implementation of 3T's practices. Therefore, in this research we try to find to study these manufacturing practices within a single model with implementation guide line. The aim of this research is to review from the above listed integrations and identify similarities and differences among 3T's during practices of implementation. Based on it, this research will present developed model with implementation guide line. This research contributes an inclusive review on continuous improvement approaches principally concentrating on Total Productive Maintenance (TPM), Toyota Production System (TPS), Total Quality Management (TQM) and PDCA approaches, relationships and integration systems of 3T's. The research in keeping with detecting literature gaps, it also scrutinizes the implementation guide line.

\section{Experimental Procedure}

The methodology followed to develop the model and implementation guideline is reviewed literature from similar published articles, journals, theses, books, technical reports, case studies, presentations, methods, present state of the art on continuous improvemetnt,3 's's, the three systems connection and mutual carry out, PDCA were painstakingly revised. The research methodology included several phases.

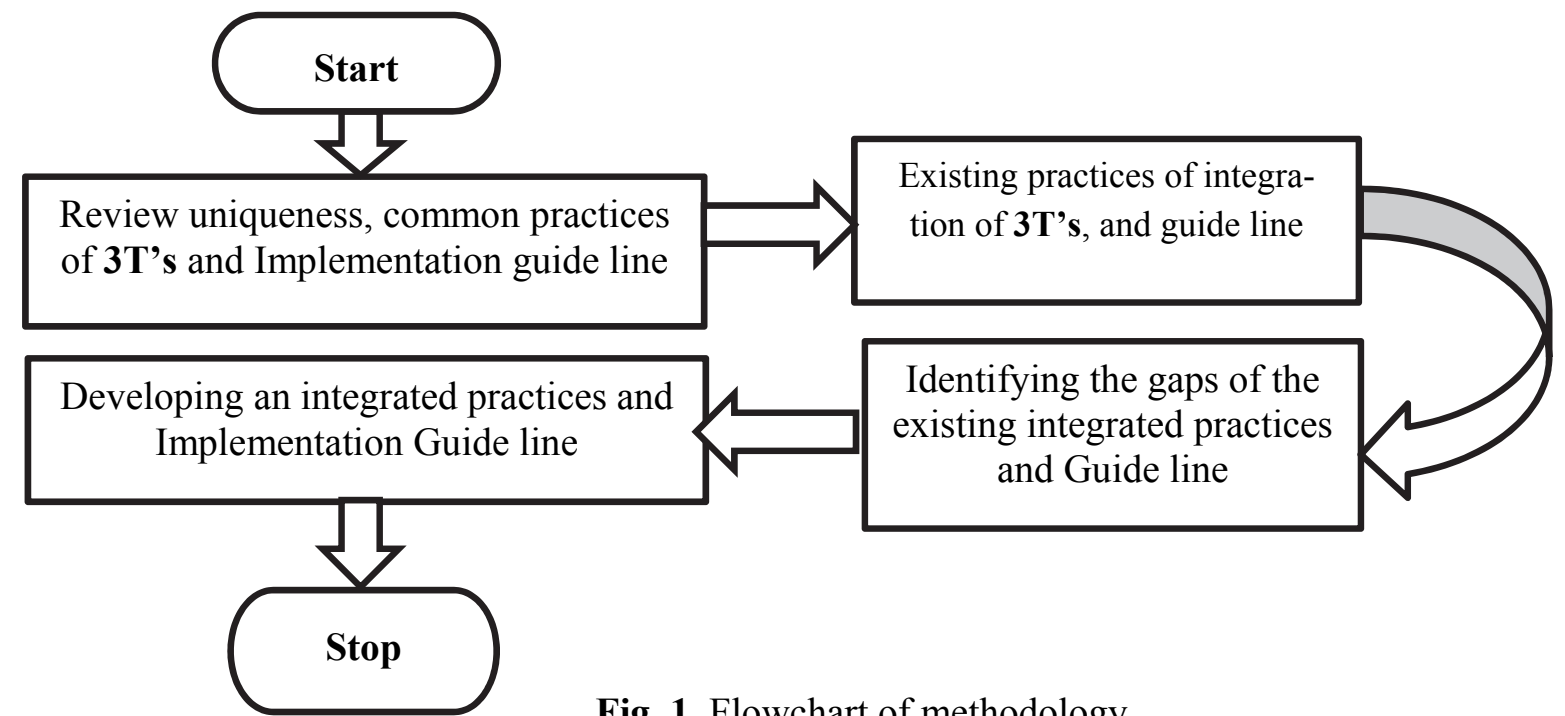

Fig. 1. Flowchart of methodology 


\section{The literature review of theoretical background of TPM, TPS, TQM \& PDCA}

\subsection{PDCA and Its Practices}

PDCA is an iterative four-step management approach used for controlling and continuously improving processes and products (Olson, 2006; Reid et al., 1999; Gidey et al., 2014). Reducing or eliminating organizational wastes and other problems have been approached through the Deming's or Shewhart's PDCA cycle (Marrs \& Mundt, 2001). Reid et al. (1999) have tried to show the detailed activities of each stage of the PDCA cycle the central theme being increasing customer satisfaction. Plan:- Create appropriate teams, Gather all available data, Understand customers' needs, Describe the process that surrounds the Problem, Determine root cause(s), Design action plan and Develop an action plan; Do:Implement improvement, Collect appropriate data, Measure progress and Document results; Check:Summarize and analyze data, Evaluate results relative to targets \& see Differences, Review any problems/errors, Record what was learned, Specify any remaining issues or unintended costs; Act:- Standardize desired improvements, Formalize "current best approach, Communicate results broadly and Identify next improvement. PDCA has got enormous applications: as a model for continuous improvement; when starting a new improvement project; when developing a new or improved design of a process; when defining a repetitive work process; and when implementing any change (Zokaei \& Simons, 2006; Gidey et al., 2014).

\subsection{TPM and Its Practices}

TPM is a methodology originating from Japan to support its TPS, since dependable and effective equipment are essential pre-requisite for implementing TPS initiatives in the organizations (Arai \& Sekine, 1998). There is a strong relationship between TPM and TPS in their developed building blocks (Singh \& Bhatia, 2015). It is clearly revealed, that TPM is the corner stone activity for most of manufacturing philosophies and can effectively contribute towards success of TPS. TPM starts with 5S According to (Singh \& Bhatia, 2015). It is a systematic process of housekeeping to achieve a serene environment in the work place involving the employees with a commitment to sincerely implement and practice housekeeping. If this $5 \mathrm{~S}$ is not taken up seriously, then it leads to 5D delays, defects, dissatisfied customers, declining profits, and demoralized employees. TPM focus on improvement in equipment availability, performance and quality with assuring health and safety of employees and protection of environment. TPM as maintenance strategy is a comprehensive strategy, hence integrating it with TQM makes the approach more versatile and flexible (Boateng et al., 2016). Total Productive Maintenance (TPM) is mediator of TQM and Business Performance in order to improve quality, flexibility, cost, and time in the context of manufacturing industry (Konecny \& Thun, 2011; Ahmad et al., 2012; Ahmad et al., 2015 ) their finding was supported by (Seth \& Tripathi, 2006; Konecny \& Thun, 2011). This is also right with (Nakajima, 1988) who states that the objectives of TPM are zero breakdown and zero defects

to improve productivity and quality, to reduce inventory and delivery cycle time, and to improve safety and employee morale. TQM and TPM have similar goals for continuous improvement, waste reduction and improving performance (Teeravaraprug et al., 2011). These practices are a comprehensive set of manufacturing improvement practices directed towards improving business performance. TPS eliminates waste through inventory control and reduction time delay of process (Rosemary \& Cherly, 2002). TPM helps maximize equipment performance and prevents break-down and TQM aims to maintain and improve product quality and business performance. The common ground of TPM \& TQM is the focus on human resources. Simultaneous implementation of TPM \& TQM, supported by human resource practices, have a significant potential to improve plant performance (Konecny \& Thun, 2011). An integrating TPM and TQM strategically over a period of time can contribute to significant increases in the Overall Equipment Effectiveness of machines thereby contributing towards realistic gains in productivity and manufacturing performance enhancements (Boateng et al., 2016). Like the concept of TQM, TPM is focused on improving all the big picture indicators of manufacturing success (Marcus, 2004; Ahuja \& Khamba, 2008). TPM implementation requires a long-term commitment to achieve the 
benefits of improved equipment effectiveness through training, management support, and teamwork. The basic practices of TPM are often called the pillars or elements of TPM. The entire structure of TPM is built and stands, on eight pillars (Singh \& Kumar, 2017; Boateng, et al., 2016). Autonomous maintenance; Focused maintenance; Planned maintenance; Quality maintenance; Education \& training; Office TPM; Development management; Safety, health \& environment (Ireland \& Dale, 2001; Rodrigues \& Hatakeyama, 2006).

McKone et al. (1999) provides a better understanding of the relationships among TPM, JIT and TQM for supporting the successful implementation of TPM. As regards the contributions of TPM on manufacturing performance (MP), Miyake (1999) have studied the application of JIT, TQC and TPM paradigms to improve manufacturing systems performance at shop floor level involving technical staff, foremen and workers. Seth and Tripathi (2005) have investigated critical significant factors like leadership, process management and strategic planning, equipment management and focus on customer satisfaction, for the effective adaptation of TQM and TPM programs. This is also supported by (Ahuja \& Khamba, 2008a). After reviewing articles on TPM practices such as Paranitharan and Babu (2014), Harsej and Yusof (2011), Abdallah and Matsui (2007), Cua et al. (2001), McKone and Weiss (1999), McKone et.al. (1999), Milling et.al. (1998), Tsuchiya (1992), Takahashi and Osada (1990), Nakajima (1988), the most regularly cited practices of TPM can be constructed as given in Table 1 below.

\section{Table 1}

Most Extensively Cited Practices of TPM

\begin{tabular}{|c|c|c|c|c|c|c|c|c|c|c|c|c|c|c|c|c|c|c|c|c|c|}
\hline \multirow{2}{*}{ Author(s) } & \multicolumn{21}{|c|}{ TPM practices } \\
\hline & - & $\sim$ & m & 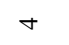 & $n c$ & $0 r$ & $\infty$ & $a$ & $ㅇ$ & $=$ & $\simeq$ & $\cong$ & $\Xi$ & $\cong$ & 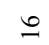 & $\simeq$ & $\stackrel{\infty}{\sim}$ & 2 & ¿ & $\vec{\sim}$ & ป \\
\hline Paranitharan and Babu (2014) & & & & $\sqrt{ }$ & $\sqrt{ } \quad \sqrt{ }$ & $\sqrt{ }$ & & & & & & 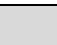 & 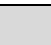 & 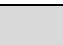 & $\sqrt{ }$ & $\sqrt{ }$ & $\sqrt{ }$ & $\sqrt{ }$ & $\sqrt{ }$ & $\sqrt{ }$ & $\sqrt{ }$ \\
\hline Harsej and Yusof (2011) & & & & $\sqrt{ }$ & $\sqrt{ }$ & & $\sqrt{ }$ & $\sqrt{ }$ & $\sqrt{ }$ & $\sqrt{ }$ & $\sqrt{ }$ & $\sqrt{ }$ & & & & & & & & & \\
\hline Abdallah and Matsui (2007) & $\sqrt{ }$ & $\sqrt{ }$ & & & & & & & & & & & $\sqrt{ }$ & $\sqrt{ }$ & & & & & & & \\
\hline Cua et al. (2001) & & & $\sqrt{ }$ & $\sqrt{ }$ & $\sqrt{ } \quad \sqrt{ }$ & $\sqrt{ }$ & $\sqrt{ }$ & $\sqrt{ }$ & & & & & & & & & & & & & \\
\hline McKone and Weiss (1999) & $\sqrt{ }$ & $\sqrt{ }$ & & & $\sqrt{ }$ & & $\sqrt{ }$ & & & & & & & & & & & & & & \\
\hline McKone et al. (1999) & $\sqrt{ }$ & & & & $\sqrt{ }$ & $\sqrt{ }$ & $\sqrt{ }$ & & & & & & & & & & & & & & \\
\hline Milling et al.(1998) & $\sqrt{ }$ & & & & $\sqrt{ }$ & $\sqrt{ }$ & $\sqrt{ }$ & & & & & & & & & & & & & & \\
\hline Tsuchiya (1992) & $\sqrt{ }$ & $\sqrt{ }$ & & & $\sqrt{ }$ & & $\sqrt{ }$ & & & & & & & & & & & & & & \\
\hline Takahashi and Osada (1990) & $\sqrt{ }$ & $\sqrt{ }$ & & & & & $\sqrt{ }$ & & & & & & & & & & & & & & \\
\hline Nakajima (1988) & $\sqrt{ }$ & $\sqrt{ }$ & & & & & $\sqrt{ }$ & & & & & & & & & & & & & & \\
\hline
\end{tabular}

\subsection{TPS and Its Practices}

The Toyota production system represents a manufacturing culture of continuous improvement based on setting standards aimed at eliminating waste through participation of all employees. The goal of the system is to reduce the timeline from the time an order is received until the time it is delivered to the actual customer. Ideally the system strives to produce the highest possible quality, at the lowest possible cost, with the shortest lead-time possible. According to Liker (2004) and Thakur (2016), there are two primary pillars of the system. The first and most famous pillar of the system is Just In Time (JIT). The JIT concept aims to produce and deliver the right parts, in the right amount, at the right time using the minimum necessary resources. But, it is not feasible in a place where there is no quality in station. JIT reduces inventory, and strives to prevent both early and over production. Producing in a JIT fashion exposes problems quickly. There are several important components to JIT: Setup time reduction, JIT schedule, JIT layout/Equipment layout, JIT delivery by suppliers, Pull system/Kanban. The second pillar is Jidoka. Ordinarily mean automatic or automation which means build in quality. Automation describes a feature of machine design to effect the principle of jidoka used in the Toyota production 
system as a pillar (Friedli et al., 2013). This is very fundamental system for manufacturing industries since it makes problems visible which is not characterized by JIT. This system also contains quite a lot of components: automatic stops, Andon, Person-Machine Separation, Error Proofing, In-station Quality Control, Solve Root Cause of Problems (5 Whys). As obviously known, the ultimate goals of TPS or combination of JIT and JIDOKA is to ensure Best Quality, Lowest Cost, Shortest Lead Time, Best Safety and High Morale through shortening the production flow by eradicating wastes. This result is achieved if and only if the following points exist. First, establishing levelled production, stable \& standardized processes, 5S (Visual Management) and Toyota Way Philosophy of the 4 P's. Second, before implementation selection of skilled people and team work through continuous improvement following PDCA cycle (Thakur, 2016). These are enablers for TPS to be successful. They should be stable for the two pillars to stand steadily. The components of the pillars work together to create the whole TPS. TPS system is simultaneously implemented with TQM and TPM will result in higher performance than implementation of practices and techniques from only one of TQM, JIT and TPM (Cua et al., 2001). TPS requires an essential ingredient "TPM" since it can only be improved availability when breakdowns, minor stops, quality defects and rework have all been eliminated. TPS has become the world best production system due to its flexibility and reduced lead time drastically by eliminating mura, muri and seven types of wastes.

Tesfayea and Kitaw (2017) also proved that industries have to undergo a total revolution in all the dimensions of the integrated JIT and TQM practices to improve their global competitiveness. Getachew et al. (2017) also showed as most of studies addressed that a synergy of JIT and TQM improvement philosophy delivers better results. JIT philosophy aims at minimizing inventory (Zero Inventory) while TQM strives for Zero defect. JIT practices can be seen into four dimensions (Flynn et al., 1995; Getachew et al., 2017) Kanban Control, Lot-size reduction JIT scheduling activities and Setup time reduction over to work on a group of different parts. After reviewing articles on TPS practices such as Tesfayea and Kitaw (2017), Getachew et al. (2017), Dametew et al. (2017), Thakur (2016), Shrivastava and Sridhar (2015), Muthoni (2015), Paranitharan and Babu (2014), Liker (2004), Cua et al. (2001), Nakamura et al. (1998), Flynn et al. (1995), Mullarkey et al. (1995) the most regularly cited practices of TPS can be constructed as given in Table 2 below.

Table 2

Most Extensively Cited Practices of TPS

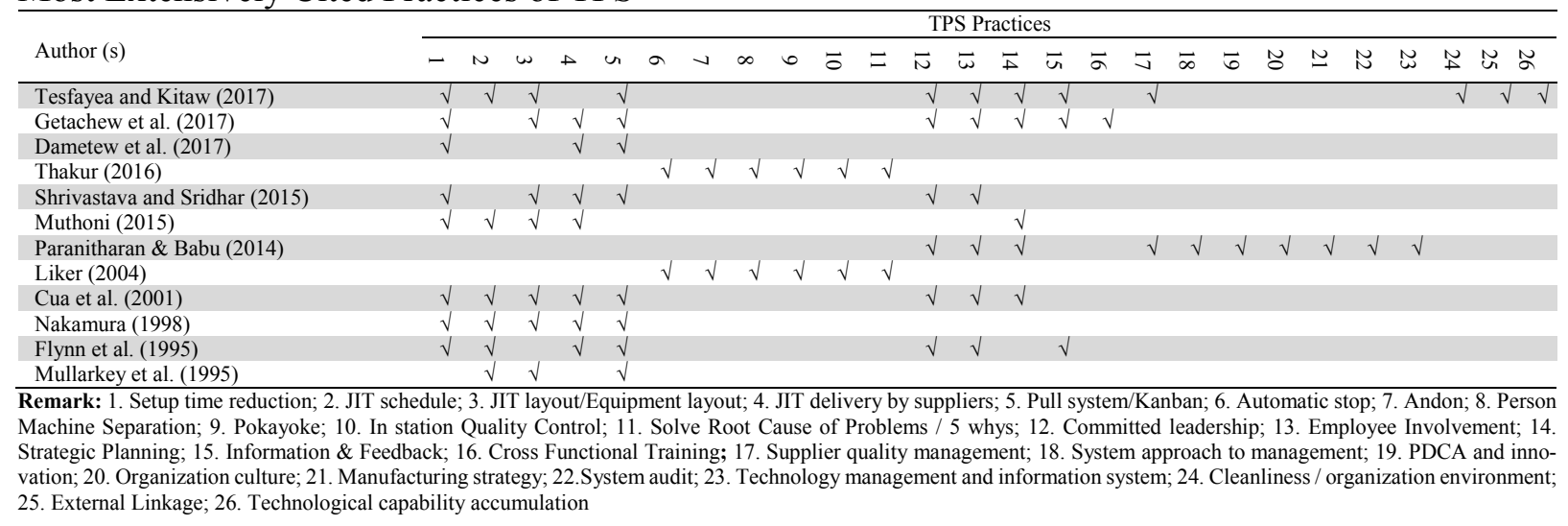

\subsection{TQM and Its Practices}

Total quality management (TQM) is an approach for improving the quality of goods and services (Getachew et al., 2017). A continuous improvement process, customer driven quality, production without defects are the main backbone of TQM. TQM is a wider philosophy of management for continuously improving the quality of products and process to achieve customer satisfaction. Organizations must build quality into products and process, and that everyone in the organization has responsibility in his effort. A successful TQM requires a committed and well-trained workforce that participates fully in 
quality improvement activities (Tesfayea \& Kitaw, 2017). TQM is an approach to improve effectiveness, flexibility, and competitiveness of a business to meet customers' requirements (Oakland, 1993) as a source of enhancing organizational performance through continuous improvement in organization's activities (Tesfayea \& Kitaw, 2017). TQM was based on Deming's 14 points and embraced a philosophy that involves 4 major areas: Managerial responsibility for continuous improvement, Focusing on the work processes to achieve improvements, Using statistics to measure process performance, Employee involvement and empowerment (Tesfayea \& Kitaw, 2017). TQM indicates a general philosophy of concerted effort, which begins with clear goals defined by top management commitment, and goes with the organized development and deployment of quality improvement plans. Similarly as discussed above, the practices of TQM is also integrated with TPM and TPS. Flynn et al. (1995) also asserted that the use of TQM practices, for instance, is crucial to reduce manufacturing process variance, and this in turn improves JIT performance. After reviewing articles on TQM practices such as Tesfayea and Kitaw (2017), Getachew et al. (2017), Thakur (2016), Shrivastava and Sridhar (2015), Muthoni (2015), Paranitharan and Ramesh (2014), Jaafreh (2013), Zu (2009), Arawati et al. (2009), Sila (2007), Sila (2006), Sila and Ebrahimpour (2005), Tari et al. (2007), Anh and Matsui (2007), Prajogo and Sohal (2006), Kaynak and Hartley (2005), Cua et al. (2001), Agus (2005), McKone and Weiss (1999), McKone et.al. (1999), Flynn et al. (1995), Tsuchiya (1992), Takahashi and Osada (1990), Nakajima (1988) the most regularly cited practices of TQM can be constructed as given in table 3 below.

Table 3

Most Extensively Cited Practices of TQM

\begin{tabular}{|c|c|c|c|c|c|c|c|c|c|c|c|c|c|c|c|c|c|}
\hline \multirow[t]{2}{*}{ Author (s) } & \multicolumn{17}{|c|}{ Practices of TQM } \\
\hline & 1 & 2 & 3 & 4 & 5 & 6 & 7 & 8 & 9 & 10 & 11 & 12 & 13 & 14 & 15 & 16 & 17 \\
\hline Tesfayea and Kitaw (2017) & $\sqrt{ }$ & $\sqrt{ }$ & $\sqrt{ }$ & $\sqrt{ }$ & $\sqrt{ }$ & $\sqrt{ }$ & $\sqrt{ }$ & $\sqrt{ }$ & $\sqrt{ }$ & $\sqrt{ }$ & & & & & & & $\sqrt{ }$ \\
\hline Getachew et al (2017) & l & $\sqrt{ }$ & $\sqrt{ }$ & $\sqrt{ }$ & $\sqrt{ }$ & $\sqrt{ }$ & $\sqrt{ }$ & $\sqrt{ }$ & & & & & & & & & \\
\hline Dametew et al. (2017) & $\sqrt{ }$ & & $\sqrt{ }$ & & $\sqrt{ }$ & & & & & & & & $\sqrt{ }$ & & & & \\
\hline Thakur (2016) & & & & & & & & & & & & & & & & & \\
\hline Shrivastava and Sridhar (2015) & $\sqrt{ }$ & & & & & $\sqrt{ }$ & & & & & & & & & & & \\
\hline Muthoni (2015) & & & & & $\sqrt{ }$ & & & & & & & & & & & & \\
\hline Paranitharan and Babu (2014) & $\sqrt{ }$ & $\sqrt{ }$ & $\sqrt{ }$ & $\sqrt{ }$ & & - & & & & & $\sqrt{ }$ & $\sqrt{ }$ & $\sqrt{ }$ & $\sqrt{ }$ & $\sqrt{ }$ & $\sqrt{ }$ & \\
\hline Jaafreh (2013) & $\sqrt{ }$ & $\sqrt{ }$ & $\sqrt{ }$ & $\sqrt{ }$ & $\sqrt{ }$ & $\sqrt{ }$ & & & & & & & & & & & \\
\hline $\mathrm{Zu}(2009)$ & $\sqrt{ }$ & $\sqrt{ }$ & $\sqrt{ }$ & $\sqrt{ }$ & $\sqrt{ }$ & $\sqrt{ }$ & & & & & & & & & & & \\
\hline Arawati et al. (2009) & $\sqrt{ }$ & $\sqrt{ }$ & $\sqrt{ }$ & $\sqrt{ }$ & $\sqrt{ }$ & $\sqrt{ }$ & & & & & & & & & & & \\
\hline Sila and Ebrahimpour (2005) & $\sqrt{ }$ & $\sqrt{ }$ & $\sqrt{ }$ & $\sqrt{ }$ & $\sqrt{ }$ & $\sqrt{ }$ & & & & & & & & & & & \\
\hline Tari et al. (2007) & $\sqrt{ }$ & $\sqrt{ }$ & $\sqrt{ }$ & $\sqrt{ }$ & $\sqrt{ }$ & $\sqrt{ }$ & & & & & & & & & & & \\
\hline Anh and Matsui (2007) & & $\sqrt{ }$ & $\sqrt{ }$ & $\sqrt{ }$ & & & & $\sqrt{ }$ & $\sqrt{ }$ & & & & & & & & \\
\hline Sali (2006) & $\sqrt{ }$ & $\sqrt{ }$ & $\sqrt{ }$ & $\sqrt{ }$ & $\sqrt{ }$ & $\sqrt{ }$ & $\sqrt{ }$ & & & & & & & & & & \\
\hline Prajogo and Sohal (2006) & $\sqrt{ }$ & $\sqrt{ }$ & $\sqrt{ }$ & 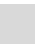 & $\sqrt{ }$ & $\sqrt{ }$ & & & & & & & & & & & \\
\hline Kaynak and Hartley (2005) & $\sqrt{ }$ & $\sqrt{ }$ & $\sqrt{ }$ & $\sqrt{ }$ & & $\sqrt{ }$ & & & & & & & & & & & \\
\hline Cua et al. (2001) & $\sqrt{ }$ & $\sqrt{ }$ & $\sqrt{ }$ & $\sqrt{ }$ & $\sqrt{ }$ & $\sqrt{ }$ & & $\sqrt{ }$ & $\sqrt{ }$ & & & & & & & & \\
\hline Agus (2005) & $\sqrt{ }$ & $\sqrt{ }$ & 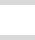 & $\sqrt{ }$ & $\sqrt{ }$ & $\sqrt{ }$ & & $\sqrt{ }$ & & & & & & & & & \\
\hline McKone and Weiss (1999) & & & & & & & & & & & $\sqrt{ }$ & & & & & & \\
\hline McKone et.al. (1999) & & & & & & & & & & & $\sqrt{ }$ & & & & & & \\
\hline Flynn et al. (1995) & & $\sqrt{ }$ & $\sqrt{ }$ & $\sqrt{ }$ & & $\sqrt{ }$ & $\sqrt{ }$ & $\sqrt{ }$ & $\sqrt{ }$ & & & & & & & & \\
\hline Tsuchiya (1992) & & & & & & & & & & & $\sqrt{ }$ & & & & & & \\
\hline Takahashi and Osada (1990) & & & & & & & & & & & $\sqrt{ }$ & & & & & & \\
\hline Nakajima (1988) & & & & & & & & & & & $\sqrt{ }$ & & & & & & \\
\hline
\end{tabular}

From the above three tables, it is noticed that there is no TPM or TPS or TQM practice commonly cited by all listed authors. In some of practices of TPM, TPS and TQM, there is enormous inconsistencies. As a result of this circumstance, this research tries to organized and integrate these most frequently 
cited 3T's practices which are identified in the above three tables. As a result the joint consequence can result in boosting profitability of manufacturing industries.

\section{Existing Integrated Practice of 3T's and Implementation Guide Line}

\subsection{Existing Integrated Practice of TPM, TPS \& TQM}

The researcher reviewed previously few developed integrated frame work and critical factors for TPM, TPS and TQM practices.

Cua et al. (2001) developed an integrated frame work of TQM, JIT, TPM. The unique practices of TQM are cross functional product design, process management, supplier quality management, customer involvement. Unique practices of JIT are setup time reduction, pull system production, JIT delivery by suppliers, equipment layout. Unique practices for TPM are autonomous and planned maintenance, technology emphasis, proprietary equipment development. Common practices for three systems are committed leadership, strategic planning, cross functional training, employee involvement, information and Feedback.

Abdallah and Matsui (2007) developed a research framework of integration of TPM and JIT. Unique practices of TPM are autonomous maintenance, preventive maintenance, maintenance support, team based maintenance. Unique practices of JIT are equipment layout, JIT delivery by suppliers, Kanban / pull system, setup time reduction, and repetitive nature of master schedule. Common competitive performances are cost, quality, flexibility, delivery, on time product launch.

Paranitharan and Babu (2014) identified 10 common critical success factors for integrated manufacturing practices of TPM, TPS and TQM: visionary leadership and management commitment, system approach to management, Customer focus and satisfaction, PDCA and innovation, organization culture, workforce management, supplier quality management, manufacturing strategy, resource planning and system audit, technology management and information system.

Dametew et al. (2017) developed conceptual model for integration of TQM and JIT. The unique practices of JIT are time and pull system. Unique practices of TQM are quality culture, top management (vision, planning and support), and process management. Common practices of TQM and JIT are People involvement (Customer, Supplier, employee, commitment, Continuously monitor, evaluation and control the process, Feedback, External relations); Manufacturing systems (Flow, Technology, Innovation, Quality team, training, customer expectations, process performance evaluation, Flexibility); Resource Utilization and Related issue (Cost, Waste Controlling mechanism, Warehouse, Logistics).

Getachew et al. (2017) developed Synergistic Model of TQM and JIT. The unique practices of TQM are cross functional product design, process management, supplier quality management, customer involvement, quality rate improvement. Unique practices of JIT are setup time reduction, pull system production, JIT delivery by suppliers, equipment layout, and availability improvement. Common practices of TQM and JIT are committed leadership, strategic planning, cross functional training, employee involvement, information and feedback (human and strategic oriented common practices) followed by PDCA Cycle.

Tesfayea and Kitaw (2017) developed an innovative JIT and TQM integrated model. Unique practices of TQM are cross-functional product design, customer involvement / focus, process management/ control. Unique practices of JIT are setup time reduction, JIT schedule, JIT layout / equipment layout, Pull system. Common practices of TQM \& JIT are strategic planning, top management commitment, cleanliness/ organization or plant environment, workforce management / employee involvement, supplier 
quality involvement / supplier relationship, information feedback and communication, external linkage, technological capability accumulation process.

Considering the work of Tesfayea and Kitaw (2017), Getachew et al. (2017), Dametew et al. (2017), Cua et al. (2001), Gunn (1988), Flynn et al. (1995) noted the difficulty faced by many authors to exactly list out the practices that encompass 3T's.

In general, it is observed from literatures that by combining all three, manufacturing profitability can be achieved through elimination any wastes. It can also be decided that the major elements of TPM and TPS are entrenched in more wide-ranging TQM package. Some of the authors described that TQM has much broader focus on improving the overall effectiveness of an organization and should be implemented before other systems are implemented. The researchers argue that before implementation of TQM, the enablers or critical success factors and the foundations for successfully completion of the integration should be first implemented. The above existing TPM, TPS and TQM practices in literatures are not corresponding, this research provides an associated result by identifying the most widely found practices of 3T's in literatures. For the moment, these most extensively quoted practices of 3T's can be divided into unique practices to 3T's separately and common practices to three of the packages as used in (Tesfayea \& Kitaw, 2017; Getachew et al., 2017; Dametew et al., 2017; Singh \& Bhatia, 2015; Cua et al., 2001). None of the earlier works on integrating TPM, TPS and TQM practices like Tesfayea and Kitaw (2017), Getachew et al. (2017), Singh and Bhatia (2015), Cua et al. (2001) provided these types of complete listing given in this research. Hereafter, this research fills this gap by combining the available 3T's practices for manufacturing industries profitability.

Therefore, based on the above reviews the unique and common practices of the three systems is presented. Unique Practices of TPM are Autonomous maintenance, Maintenance support, Team based maintenance, Planned Maintenance, Proprietary Equipment Development and Technology emphasis. Unique Practices of TPS are Automatic stop, Andon, Person machine separation, Pokayoke, In station quality control, Solve root cause of problems / 5 whys, JIT schedule, Setup time reduction, JIT layout / Equipment layout, JIT delivery by suppliers, Pull system / Kanban, Availability improvement. Unique Practices of TQM are Customer involvement / Focus, Process management or statistical process control, Cross-functional product design, Quality rate improvement.

Common Practices of TPM, TPS and TQM or Human and Strategic Oriented Common Practices are Committed leadership / management support, Strategic planning, Workforce management / Employee involvement, Supplier quality involvement/supplier relationship, Feedback and Communication, Cleanliness and Organizational Environment, External linkage, Cross functional training, Technological accumulation and re-planning, External sources of technologies and knowledge, Manufacturing systems, Resource utilization and related issues.

\subsection{Existing Practices of Implementation Guide Line}

Even though there is no previously developed implementation guide line specifically for integrated TPM, TPS and TQM practices, the researchers tried to review few existing separately developed implementation frameworks of 3T's and implementation frame work integrated JIT \& TQM practices. Nakajima (1988) Application of TPM Program has 12 Steps under the category of four main stages. Stage I. Preparation, Stage II. Preliminary Implementation, Stage III. TPM Implementation and Stage IV. Stabilization.

Allen et al. (2001) presented TPS implementation process for successful application of the TPS pillars. They divide the program into three main stages such as: Stage I: Preparation stage (Bhasin et al., 2012; Tourki, 2010). Stage II : Design stage (Atkinson, 2004 ; Tourki, 2010). Stage III: Implementation stage (Tourki, 2010). 
Beshah and Kitaw (2014) generalized TQM implementation model from the following quality guru's: Juran quality trilogy (planning, control, improvement) proposed ten-point plan towards quality implementation); Philip B. Crosby 14 steps to quality improvement program; Feigenbaum proposed nineteen steps for quality improvement endeavor. Based on it, major steps followed by any organization when implementing quality management are: Step 1: Understanding; Step 2: Top management commitment; Step 3: Company-wide awareness; Step 4: Planning; Step 5: Implementation; Step 6: Review

Getachew et al. (2017) also developed implementation framework for integrated JIT \& TQM practices. They categorized the framework in to six stages. Stage 1: Initial gap assessment; Stage 2: Plan for improvement; Stage 3: Training; Stage 4: Basic practices implementation; Stage 5: System integration; stage 6: Implementation of visual control system.

\section{Gaps in the existing integrated TPM, TPS \& TQM practices, and implementation guideline}

\subsection{Gaps in the Existing Integrated TPM, TPS \& TQM Practices}

The researchers debate that the existing TPM, TPS and TQM integrated approaches (Tesfayea \& Kitaw, 2017; Getachew et al., 2017; Dametew et al., 2017; Singh \& Bhatia, 2015; Cua et al., 2001) are not corresponding. This research provides a combined result as shown in identified common practices. Furthermore, the existing integrated approaches of TQM and JIT; JIT and TPM; JIT, TPM and TQM did not show integration strong practices by following PDCA cycle approach even though. Getachew et al. (2017) tried to show on the top of the integrated framework of JIT and TQM. These recent studies did not include the TPM and one pillar of TPS which is JIDOKA. However, Cua et al. (2001) developed an integrated framework of TPM, JIT and TQM, it does not include focused improvement which is very fundamental for assessment of equipment failures and JIDOKA which is critical for problem solving. As we know, TPM strives for zero breakdown, zero accident \& zero defects and JIDOKA built quality in station these all together enhancing the productivity and quality of products / services and have high impact on elimination of wastes and minimizing costs to enable the industry more profitable. So that, the journey towards becoming profitable industry is not easy and it is not a quick win. But, better understanding of TQM, TPM and TPS concepts and the ability to integrate all 3 T's decides the success for profitability. Besides, implementing 3 T's should not be in order, rather it should be parallel.

The existing developed frame works from different researchers missed the following three key points.

- Conceptual Foundation of Mind-set \& attitude, Genuine participatory industry culture, Employee trust and empowerment (Rehder, 1989; Cua et al., 2001).

- Kaizen Basics of 5S, Workplace \& operation standardization, Waste elimination (Dametew et al., 2017; Tsuchiya, 1992; Ananthanarayanan, 2006; Becker, 2001; Khamis et al., 2009; Yusof \& Aspinwall, 2001; Ho et al., 1995; Kumar et al., 2006; Sharma \& Singh, 2015; Ahuja \& Khamba, 2008; Moradi et al., 2011).

- Policy Management and Deployment for formulation of mission, vision, objectives, business policies by exercising Cross SWOT analysis. Different authors agreed that integration of 3T's practices are addressed by few studies, additional gaps include: Most of the research's focused on the validation of the joint philosophies can enhance organizational performance. Thought there is few researches on the integration of the practices still there exists ambiguity on synergizing the philosophies as a single program. Several authors agree that 3T's practices are embedded on each other and one of the three practices should not be implemented first before implementing another practice from three. The above listed three key points and common practices should be implemented first. There is no prepared implementation guideline for successful implementation of integrated model of 3T's practices. However, Getachew et al. (2017) tried to present implementation guideline which missed two key points. For that reason, 3T's need implementation guide line based on PDCA cycle 
similar with Zokaei and Simons (2006), Gidey et al. (2014) to be responsible for the compulsory integration to simplify in the implementation to make standard on every step of the cycle for every

processes. For this aftermath this research will try to fill the gap by developing an integrated model of 3T's through the Deming or Shewharts' cycle of PDCA approach.

\subsection{Gaps in the Existing Implementation Guide Line}

There is no standardized implementation guideline as shown in the above very few developed frame works. The researchers argue that these guide lines are not corresponding and have a gap. Getachew et al. (2017) developed framework for application of integrated JIT and TQM practices are summarized on two main points. Initial gap assessment planning and training are main activities categorized under preparation phase; $5 \mathrm{~S}$ implementation, system integration and visual control system implementation are main activities categorized under implementation phase (Bhasin et al., 2012; Atkinson, 2004; Tourki, 2010). Beshah and Kitaw (2014) developed steps for implementation of TQM are merged in to three main points. Understanding, Top management commitment, Company-wide awareness, Planning are categorized under preparation phase; Implementation and review are categorized under implementation and stabilization phases respectively. Allen et al. (2001) developed three stages of TPS implementation frame work, even though the frame work is lacking few critical points, the researchers agreed with the developed stages of preparation, design and implementation stage. Nakajima (1988) developed implementation stages are summarized in to three main points. Preparation and Preliminary Implementation are categorized under preparation phase; Implementation and Stabilization are the other two phases for implementation of TPM.

In general, the existing few studies are missing the following critical points for successful application of integrated 3T's practices. Designing phase which includes policy management; Stablization phase which include review, evaluation and standardization; Sustaining phase which include recognition \& reward, best practicing, regular capacity building as shown in the new developed implementation guide line for new developed integrated 3T's model.

\section{An Integrated New TPM, TPS \& TQM Model and Implementation Guide Line}

\subsection{An Integrated New TPM, TPS \& TQM Model}

For manufacturing industries to attain heightened performance, sustainable competitive advantages, and ultimately global success, this research proposes a new 3T's integrated model and literature based implementation guide line. So, for effectiveness of the integrated model and implementation guide line, following and application of PDCA cycle is unquestionable. Therefore, without following PDCA approach in every implementation process of an integrated model of 3T's, boosting profitability is not possible. Total productive maintenance (TPM) has proved that availability of equipment and occupational safety, healthy and environment are fundamentally important. Toyota production system has confirmed the importance of reducing inventories and eliminating waste by building quality in station. Total quality management (TQM) has also substantiated that customer service and product quality are important. Manufacturing industries can carry on from end to end with the solutions that fills the identified gaps and common practices identified as shown in integrated practices of 3T's. The exceptional practices of each systems can go in parallel by integrating with PDCA cycle. For successful application of the developed model, the implementation guide line should framed based on PDCA approach. The universal tactic of this integrated model can be clarified as follows: the anticipated 3T's integrated model has TPM, TPS and TQM unique and common practices. The 3T's practices of most commonly cited by few previous researchers is included. Besides, common practices not cited by these authors but found in literature are added to the new model. Because, these practices are very critical for successful implementation of the developed integrated model. Conceptual foundation, Basic kaizen activ- 
ities, Policy management. The goal of the proposed model is to bring profitability through the implementation of PDCA cycle. During the implementation of the integrated model, quantitative and qualitative results achieved should be standardized, maintained and improved by continuously following the PDCA approach.

The new 3T's integrated developed model is different from the existing TPM, JIT and TQM; TPM and JIT; TQM and JIT integrated frameworks recommended by existing literatures of (Cua et al., 2001; Abdallah \& Matsui, 2007; Paranitharan \& Babu, 2014; Getachew et al., 2017; Tesfayea \& Kitaw, 2017; Dametew et al., 2017) as shown in the gaps existing integrated TPM, TPS \& TQM Practices. The proposed framework is ground-breaking framework as it helps industries to secure their profit. Besides, the developed model will add value to both academicians and practitioners who are consulting on the manufacturing industries.

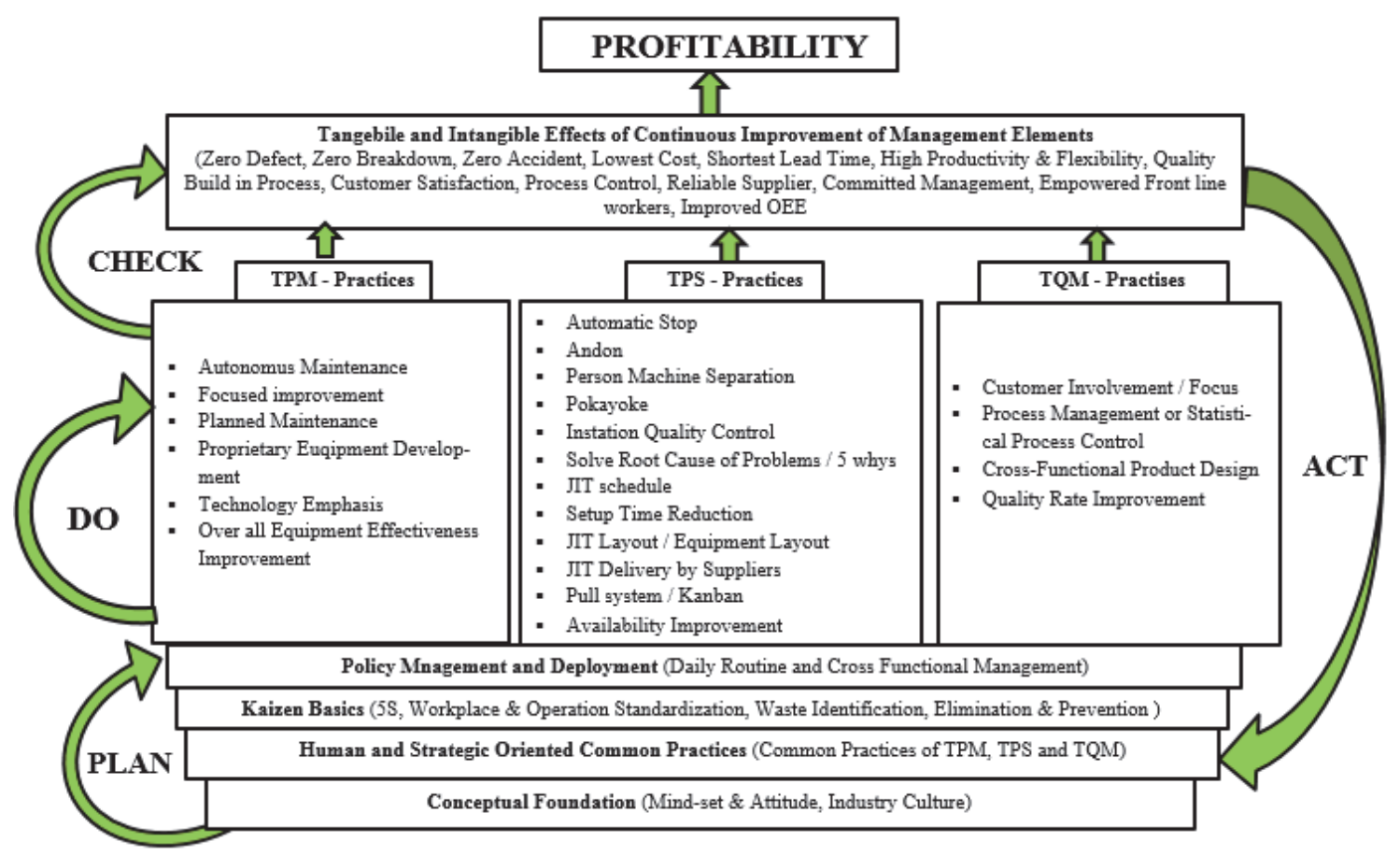

Fig. 2. Cutting-edge TPM, TPS and TQM Integrated Model

\subsection{New Developed Implementation Guide Line}

The developed implementation guideline have five main phases. The developed implementation guide line is different from the previous very few studies of Nakajima (1988), Allen et al. (2001), Beshah and Kitaw (2014), Getachew et al. (2017). But, the researchers tried to maintain these previous few studies common main activities and added another three main activities which enables successfully application of the integration of TPM, TPS and TQM practices. Herewith is listed the five phases.

\subsubsection{Preparation Phase}

\subsubsection{Preliminary Gap Assessment}

This phase particularly focuses on assessment of the existing situations based on the 4p's of people, philosophy, process and problem solving. People-analysis of employees level of skill to receive training and solving problems using skill matrix; Process - identification of wastes or problems; Philosophy existing long term thinking by allocating resources skilled manpower, ample time, budget; Problem 
solving - assessment of the existing program and whether the 3 T's are existing on the industry or not. Based on this, customized training material (TPM, TPS, TQM and PDCA) containing representation of existing situation of the industry examples, pictures, videos etc. will be designed. Besides, conceptual foundations, Basic kaizen activities, policy management topics also include. Since these are preconditions for successful implementation of the integrated model. This is similar to Getachew et al. (2017) the gaps should target factors like organization working culture, managerial and technical.

\subsubsection{Planning Activities}

General plan regarding to the implementation of the developed model as per the guideline (time frame) will be formulated by the top management. Smooth horizontal and vertical communication, resourcefulness \& positive involvement of top managements are desired for planning activities. Top management's announcement of the program to all employees is mandatory, since it creates ownership and directed employees think towards one goal. These enables to create fertile ground for implementation. This is similar with authors of Nakajima (1988) and Getachew et al. (2017). But, the researchers argue on Getachew et al. (2017) the manager should form improvement committee. Based on the gap assessment, departments which are directly connected to the identified problems should be involved on implementation. In addition, by discussion and involvement of department managers, cross functional team members (improvement committee) are nominated. Other activates like selection of implementation pilot or model areas, duty \& responsibility of cross functional team leader and members are performed.

\subsubsection{Training}

In this phase the following main activities are going to be done. First, holding theoretical knowledge test. This enables for the trainer to know the status of trainees and s/he will focus on the identified gaps of trainees in order to fill the gap. Second, conducting management and employee's oriented training regarding to 3T's practice and technical training to fill existing skill gap on manufacturing process. 3T's practice: TPM contents - autonomous maintenance, Focused improvement, Planned maintenance, Proprietary equipment development, Technology emphasis, Over all Equipment Effectiveness. TPS contents - Automatic stop, Andon, Person machine separation, Pokayoke, In station quality control, Solve root cause of problems / 5 whys, JIT schedule, Setup Time Reduction, JIT Layout / Equipment Layout, JIT Delivery by Suppliers, Pull system / Kanban, Availability Improvement. TQM contents - Customer involvement / Focus, Process management or Statistical process control, Cross-functional product design, Quality rate improvement. Additional contents - PDCA approach; Common practices; Conceptual foundations; Basic kaizen activities; Policy management. This is also similar with (Getachew et al., 2017) Based on the gap assessment made training areas should be designed that considers employee's capability, capacity and competency and (Nakajima, 1988) Launch education program to introduce initiatives. Technical training contents depends on the nature of the manufacturing processes of industries.

\subsubsection{Design Phase}

Following the policy management missions, visions, objectives, business policies / goals, main activities to be improved are identified and determined by the positive involvement of managements. These all are accomplished by SWOT and Cross SWOT analysis. Based on it, sectional and departmental operational goals will also be formulated. So, the actions made by each level should be understandable and in accordance with the industries strategic goals. This is also similar with Bhasin et al. (2012) and Tourki (2010). It is a fundamental stage of implementation by identifying and determining of missions, aims, objectives and area or activities that need to be improved. After completion of the policy deployment, top management again holds kick off for confirmation. Nakajima (1988) also supports this holding kick-off before implementation. The researchers agree with Atkinson (2004) and Tourki (2010) after policy deployment, process mapping of system's current state is the first step of this stage in order 
to study and examine all activities and areas within the organization. Besides, program construction for 3T's implementation (developing cross functional committee implementation program, maintenance program for Operations and prevention program of planned maintenance) are also included in this phase.

\subsubsection{Implementation Phase}

The researchers totally agree with Nakajima (1988) and Getachew et al. (2017). Implementation start with simple but fundamental $5 \mathrm{~S}$ techniques of sorting, set in order, shine, standardize and sustain activities; Identification of mura, muri and muda; Work place and operation standardization; Integrating systems of technologies, people, product, process; Implementation of visual control systems like kanban. The researchers additionally present preparation and standardization of four basic autonomous maintenance activities of inspection, cleaning, lubrication and bolt-tightening; Evaluating the over all equipment effectiveness of equipment by identifying the six big losses; Equipment failures root cause analysis by focused improvement; Building quality in station by implementing JIDOKA components of andon, pokayoke, automation, 5 whys; Application of statistical tools for process control and management. The main activity that cross functional committee members should not forget is recording data for every improvement or failure. Because, this is big challenge on most of manufacturing industries. Cross functional and daily management should also taking place to identify problems and set countermeasures to solve immediately.

\subsubsection{Stabilization Phase}

This phase is also called monitoring and evaluation phase. The following crucial main activities are going to be executed. Evaluation of the implementation or system audit based on evaluation checklists. This is also supported by Tourki (2010) the new system state should be evaluated and validated in order to identify all possible opportunities for future improvement. Performing again SWOT analysis to identify rooms for improvement, management's involvement, Cross functional committee members daily management activities; Installed positive feedback providing system. Since, the positive feedback will be used to obtain the required support from decision makers. Holding progress report sessions enable to know the status of the implementation and to identify challenges. Comprehending the result (especially quantitative and qualitative results) is also another main activity which should be done by cross functional committee members in order to check whether goals are achieved or not. If the goals are not achieved, the committee is expected to check the policy deployment by designing again as shown on the new developed model of integrated 3T's practices. But, if the goals are achieved, the organization secured perfection of implementation of 3T's integrated model.

\subsubsection{Sustaining Phase}

This is the final phase of implementing guideline of new integrated model. The critical activities performing on this phase are establishing recognition and rewarding system. Based on the audit result, manufacturing industries are expecting to recognize and reward for best performers. The committee prepares best practice manual. Best practice is another key factor for scaling up the implementation. Transformation of new systems to another sections will be executed either by the existing Cross functional committee members or new formed committee members. The last, but not least activity that should regularly holding is capacity building by education and training regarding to the latest integrated 3T's practices. This is very challengeable phase for any manufacturing industries. 


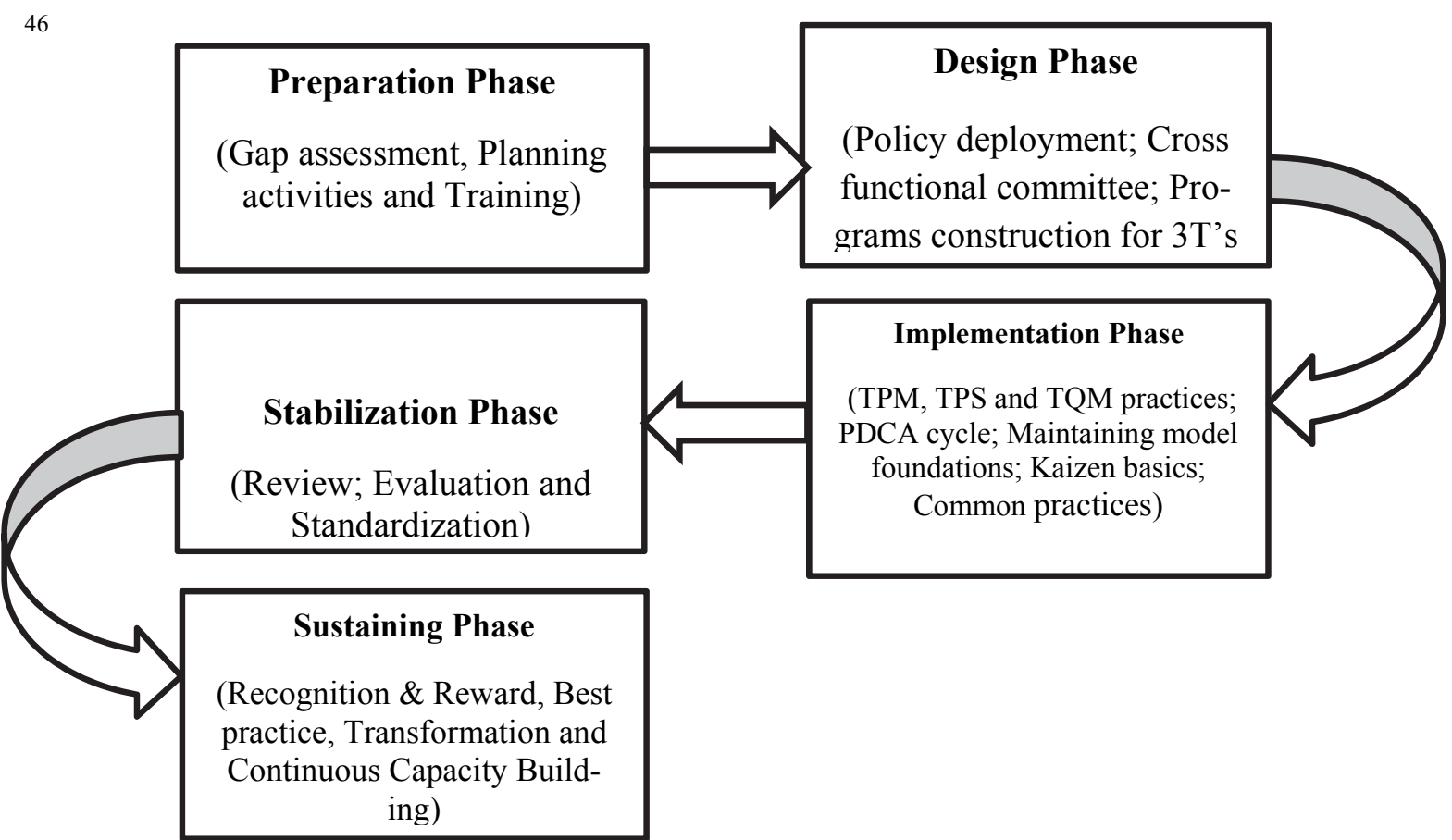

Fig. 3. Developed Implementation Guide line

\section{Conclusion}

Manufacturing industries should be profitable to compete and survive on the global market. This is achieved by producing good quality of products with zero defect, zero breakdown, zero accident, by reducing inventories and costs, with shorter lead time, better flexibility and built quality in station. So, introducing continuous improvement way of life is compulsory. Few previous studies showed that an integration of TPM, TPS and TQM practices brings superior outcomes. TPM targets at zero break down, zero defect and zero accident by maintaining the overall equipment effectiveness. TPS ambitions at eliminating wastes and improving the availability of materials (raw material, semi-finished, finished, spare parts, accessories etc.) by minimizing inventory. whereas TQM make every effort for Zero defect. However the amalgamation of the three systems delivers gives superior outcome, almost none of the studies exactly addressed the integration of TPM, TPS and TQM practices. As point out in the literature review, only one research was studied on developing research frame work of integrated TPM, JIT and TQM which lacks JIDOKA and implementation guide line. Due to constraint of similar studies, the researchers forced to search and review integrated practices of JIT and TQM; JIT and TPM; Critical factors for implementation of the integration of TPM, TPS and TPM. The existing developed integrated model and research framework are not still analogous and lacks implementation guide line. Even though, one synergetic framework of JIT and TQM practices research tried to present implementation framework which lacks the critical points of three main implementation activities. As shown in the new developed implementation guide line designing, stabilizing and sustaining phase which are fundamental for an organization to be profitable. To fill this gap, this research reviewed the existing relationship between TPM, TPS and TQM practices, and previously integrated systems. Maintaining previous common practices of the three programs. In addition, a working guide line for an implementation of unique practices of TPM, TPS and TQM through PDCA cycle is proposed for manufacturing industries. The future work is application of the integration model through PDCA approach based on the developed implementation guide line to selected sectors of manufacturing industries in Ethiopia. 


\section{Acknowledgment}

Firstly, the corresponding author would like to thank God for giving me the power and courage to finish this research. Secondly, authors appreciatively acknowledges the support by assistant professor of Solomon Mengestu and Tewodros Hailu on timely providing their constructive feedback and giving me relevant materials related to this study. Last, but not least, the authors would like to thank my wife for her continuous support and adorable baby Elmiyanos Haftu for his facial expression inspired me to complete this research.

\section{References}

Abdallah, A. B., \& Matsui, Y. (2007). JIT and TPM: Their relationship and impact on JIT and competitive performances. In Conference of the International Decision Sciences Institute (DSI), Bangkok, Thailand.

Agus, A. (2005). The structural linkages between TQM, product quality performance, and business performance: Preliminary empirical study in electronics companies. Singapore Management Review, $27(1), 87$.

Ahmad, M. F., Zakuan, N., Jusoh, A., \& Takala, J. (2012). Relationship of TQM and business performance with mediators of SPC, lean production and TPM. Procedia-Social and Behavioral Sciences, 65, 186-191.

Ahuja, I. P. S., \& Khamba, J. S. (2008). Total productive maintenance: literature review and directions. International Journal of Quality \& Reliability Management, 25(7), 709-756.

Ahuja, I. P. S., \& Khamba, J. S. (2008a). An evaluation of TPM initiatives in Indian industry for enhanced manufacturing performance. International Journal of Quality \& Reliability Management, 25(2), 147-172.

Ananthanarayanan, K. R. M. (2006). Application of 5S management system in NDE laboratory. In National seminar on non-destructive evaluation.

Andersson, R., Eriksson, H., \& Torstensson, H. (2006). Similarities and differences between TQM, six sigma and lean. The TQM magazine, 18(3), 282-296.

Anh, P. C., \& Matsui, Y. (2007). Effect of Total Quality Management and Just-In-Time practices on Competitive Performance-Empirical Evidence. In POMS 18th Annual Conference.

Ahmad, M. F., Aziati, A. N., Bon, A. T., Ngadiman, Y., \& Chan, S. W. (2015). Review Relationship TPM as Mediator between TQM and Business Performance. In Industrial Engineering, Management Science and Applications, 991-996. Springer, Berlin, Heidelberg.

Arai, K., \& Sekine, K. (1998). TPM for the lean factory: Innovative methods and worksheets for equipment management. CRC Press.

Arawati, A., Ahmad, M. S., \& Muhammad, J. (2009). An empirical investigation on the impact of quality management on productivity and profitability: Associations and mediating effect. Contemporary Management Research, 5(1).

Atkinson, P. (2004). Creating and implementing lean strategies. Management Services, $48(2), 18$.

Becker, S. W. (1993). TQM does work: ten reasons why misguided attempts fail. Management Review, 82(5), 30.

Becker, J. E. (2001). Implementing 5S: To promote safety \& housekeeping. Professional Safety, 46(8), 29.

Beshah, B., \& Kitaw, D. (2014). Quality management practice in Ethiopia. African Journal of Business Management, 8(17), 1.

Bhasin, S. (2012). Performance of Lean in large organisations. Journal of Manufacturing Systems, 31(3), 349-357.

Boateng,K.A., Amissah,M., \& Boateng,O.S. (2016). Integrating total productive maintenance \& total quality management: case study in pavement block industry. International Journal of Research in Engineering and Technology, 5(4),295-300. 
Cua, K. O., McKone, K. E., \& Schroeder, R. G. (2001). Relationships between implementation of TQM, JIT, and TPM and manufacturing performance. Journal of operations management, 19(6), 675-694.

Dametew, A.W., Kitaw, D., \& Ebinger, O. (2017). The Roles of TQM \& JIT for basic metal industries global competitiveness. Industrial Engineering \& Management, 6,212.

Friedli,T., et al. (2013.). Leading pharmaceutical operational excellence, DOI 10.1007/978-3-64235161-7 2, C Springer-Verlag Berlin Heidelberg.

Flynn, B. B., Sakakibara, S., \& Schroeder, R. G. (1995). Relationship between JIT and TQM: practices and performance. Academy of management Journal, 38(5), 1325-1360.

Fullerton, R. R., \& McWatters, C. S. (2002). The role of performance measures and incentive systems in relation to the degree of JIT implementation. Accounting, Organizations and Society, 27(8), 711735.

Getachew,F., Mulugeta,A., Kitaw,D., \& Berhan, E. (2017). A synergistic frame-work of JIT \& TQM through TOC. Journal of Multidisciplinary Engineering Science and Technology,4(4), 6995-7003.

Gidey, E., Jilcha, K., Beshah, B., \& Kitaw, D. (2014). The plan-do-check-act cycle of value addition. Industrial Engineering \& Management, 3(124), 2169-0316.

Gunn, T. G. (1988). Manufacturing for competitive advantage: becoming a world class manufacturer. Ballinger Pub Co.

Harsej, F. \& Yusof,S.M. (2011). Continuous improvement through an integrated maintenance model.4(8), 353-362.

Ho, S. K., Cicmil, S., \& Fung, C. K. (1995). The Japanese 5-S practice and TQM training. Training for Quality, 3(4), 19-24.

Huang, P. (1991). World class manufacturing in the 1990s: integrating JIT, TQC, FA, and TPM with worker participation. In Modern Production Concepts, 491-507. Springer, Berlin, Heidelberg.

Imai, M. (1998). Will America's corporate theme song be" Just in Time"?. The Journal for Quality and Participation, 21(2), 26.

Ireland,F. \& Dale,B.G. (2001). A study of total productive maintenance implementation. Journal of Quality in Maintenance Engineering,7(3), 183-191.

Jaafreh, A. B., \& Al-abedallat, A. Z. (2012). The effect of quality management practices on organizational performance in Jordan: An empirical study. International Journal of Financial Research, 4(1), 93.

Kaynak, H., \& Hartley, J. L. (2005). Exploring quality management practices and high tech firm performance. The Journal of High Technology Management Research, 16(2), 255-272.

Keivan Zokaei, A., \& Simons, D. W. (2006). Value chain analysis in consumer focus improvement: a case study of the UK red meat industry. The International Journal of Logistics Management, 17(2), 141-162.

Khamis, N., Abrahman, M. N., Jamaludin, K. R., Ismail, A. R., Ghani, J. A., \& Zulkifli, R. (2009). Development of 5S practice checklist for manufacturing industry. In Proceedings of the World Congress on Engineering, 1( 3), 1-5.

Konecny, P. A., \& Thun, J. H. (2011). Do it separately or simultaneously-An empirical analysis of a conjoint implementation of TQM and TPM on plant performance. International Journal of Production Economics, 133(2), 496-507.

Krishnan, V., \& Parveen, C. M. (2013, July). Comparative study of lean manufacturing tools used in manufacturing firms and service sector. In Proceedings of the World Congress on Engineering, 1.

Kumar, M., Antony, J., Singh, R. K., Tiwari, M. K., \& Perry, D. (2006). Implementing the Lean Sigma framework in an Indian SME: a case study. Production Planning and Control, 17(4), 407-423.

Liker, J. K. (2004). The Toyota Way (2004), 14 Management Principles from the World's Greatest Manufacturer. McGrall-Hill Professional.

Liker, J. K., \& Morgan, J. M. (2006). The Toyota way in services: the case of lean product development. The Academy of Management Perspectives, 20(2), 5-20.

Marcus, D. (2004). World class maintenance. Modern Casting, 94(8), 44. 
Marrs, F. O., \& Mundt, B. M. (2001). Enterprise concept: business modeling analysis and design. Handbook of Industrial Engineering: Technology and Operations Management. New York: John Wiley \& Sons, 26-60.

McKone, K. E., Schroeder, R. G., \& Cua, K. O. (1999). Total productive maintenance: a contextual view. Journal of operations management, 17(2), 123-144.

McKone, K. E., Schroeder, R. G., \& Cua, K. O. (2001). The impact of total productive maintenance practices on manufacturing performance. Journal of operations management, 19(1), 39-58.

McKone, K.E. \& Weiss, E.N. (1999). Total productive maintenance: bridging the gap between practice and research. Production and Operations Management, 7 (4), 335-351.

Milling, P., Maier, F. H., \& Hasenpusch, J. (1998). Implementation and outcomes of total productive maintenance. papers from the 5th International Conferences of the European Operations Management Association, 304-309.

Miyake, D. I. (1999). Matching the promotion of total quality control and total productive maintenance: an emerging pattern for the nurturing of well-balanced manufacturers. Total Quality Management, 10(2), 243-269.

Moradi, M., Abdollahzadeh, M. R., \& Vakili, A. (2011). Effects of implementing 5S on total productive maintenance: a case in Iran. In Quality and Reliability (ICQR), IEEE International Conference, 4145.

Mullarkey, S., Jackson, P. R., \& Parker, S. K. (1995). Employee reactions to JIT manufacturing practices: a two-phase investigation. International Journal of Operations \& Production Management, 15(11), 62-79.

Muthoni, D. K. (2015). Factors Influencing the Adoption of Just In Time Management by Electronics Micro, Small and Medium Enterprises in Luthuli Avenue of Nairobi County in Kenya. Journal of Engineering and Economic Development, 2(1), 1.

Nakajima, S. (1988). Introduction to TPM: Total Productive Maintenance.(Translation). Productivity Press, Inc., 129.

Nakamura, M., Sakakibara, S., \& Schroeder, R. (1998). Adoption of just-in-time manufacturing methods at US-and Japanese-owned plants: some empirical evidence. IEEE Transactions on Engineering Management, 45(3), 230-240.

Oakland, J.S. (1993). Total quality management 2nd Edition. Nichols Publications Co.

Ohno, T. (1988). Toyota production system: beyond large-scale production. crc Press.

Olson, W. (2006). Systems thinking, sustainability science and engineering: defining principles. Elsevier: Technology \& Engineering, USA.

Paliwal,S., Varshney,A.R., Awana,D.S. (2013). Relationship and comparision between JIT, TQM and TPM. International Journal of Mechanical Engineering Research and Development, 3(2),61-67.

Paranitharan, K. P., \& Babu, T. R. (2014). A comprehensive review of integrated manufacturing practice in global context-manufacturing management perspective. International Business Management, 8(6), 369-377.

Powell, T. C. (1995). Total quality management as competitive advantage: a review and empirical study. Strategic management journal, 16(1), 15-37.

Prajogo, D. I., \& Sohal, A. S. (2006). The integration of TQM and technology/R\&D management in determining quality and innovation performance. Omega, 34(3), 296-312.

Rehder, R. R. (1989). Japanese transportation in Search of a balanced and broader perspective. Columbia Journal of World Business, 24(4), 17-28.

Reid, R. A., Koljonen, E. L., \& Bruce Buell, J. (1999). The Deming Cycle provides a framework for managing environmentally responsible process improvements. Quality Engineering, 12(2), 199209.

Rodrigues, M., \& Hatakeyama, K. (2006). Analysis of the fall of TPM in companies. Journal of $\quad M a-$ terials Processing Technology, 179(1), 276-279.

Roth, A. V., \& Miller, J. G. (1992). Success factors in manufacturing. Business Horizons, 35(4), 7381.

Schonberger, R. J. (1986). World class manufacturing: the lessons of simplicity applied. 
Seth, D., \& Tripathi, D. (2006). A critical study of TQM and TPM approaches on business performance of Indian manufacturing industry. Total Quality Management \& Business Excellence, 17(7), 811824.

Seth, D., \& Tripathi, D. (2005). Relationship between TQM and TPM implementation factors and business performance of manufacturing industry in Indian context. International Journal of Quality \& Reliability Management, 22(3), 256-277.

Sharma, R., \& Singh, J. (2015). Impact of Implementing Japanese 5S Practices on Total Productive Maintenance. International Journal of Current Engineering and Technology, 5(2), 818-825.

Shrivastava, R.K., \& Sridhar, K. (2015). Implementation aspects of Just in Time in indian industries. International Journal of Engineering Research \& Technology, 4(5), 1379-1387.

Sila, I. (2007). Examining the effects of contextual factors on TQM and performance through the lens of organizational theories: An empirical study. Journal of Operations management, 25(1), 83-109.

Sila, I., \& Ebrahimpour, M. (2005). Critical linkages among TQM factors and business results. International journal of operations \& production management, 25(11), 1123-1155.

Singh, N., \& Bhatia, O. S. (2015). Review Paper on: Total Productive Maintenance. International Journal of Advanced Research in Mechanical Engineering and Technology, 1(1), 21-26.

Singh, R., \& Kumar, H.(2017). Role of TPM Paradigms in Achieving Manufacturing Excellence in Industry.

Sriparavastu, L., \& Gupta, T. (1997). An empirical study of just-in-time and total quality management principles implementation in manufacturing firms in the USA. International Journal of Operations \& production management, 17(12), 1215-1232.

Takahashi, Y., \& Osada, T. (1990). TPM, total productive maintenance. Quality Resources.

Tari, J. J., Molina, J. F., \& Castejon, J. L. (2007). The relationship between quality management practices and their effects on quality outcomes. European journal of operational research, 183(2), 483-501.

Teeravaraprug, J., Kitiwanwong, K., \& SaeTong, N. (2011). Relationship model and supporting activities of JIT, TQM and TPM. Songklanakarin Journal of Science \& Technology, 33(1).

Tesfayea, G., \& Kitaw, D. (2017). A TQM and JIT Integrated Continuous Improvement Model For Organizational Success: An Innovative Framework. Journal of Optimization in Industrial Engineering, 10(22), 15-23.

Thakur, A. (2016). A Review on Lean Manufacturing Implementation Techniques: A Conceptual Model of Lean Manufacturing Dimensions.

Tourki,T. (2010). Thesis implementation of lean with in the cement industry.

Tsuchiya, S. (1992). Quality maintenance: zero defects through equipment management. Productivity Press.

Yusof, S. R. M., \& Aspinwall, E. (2001). Case studies on the implementation of TQM in the UK automotive SMEs. International Journal of Quality \& Reliability Management, 18(7), 722-744.

$\mathrm{Zu}, \mathrm{X}$. (2009). Infrastructure and core quality management practices: how do they affect quality? International Journal of Quality \& Reliability Management, 26(2), 129-149.

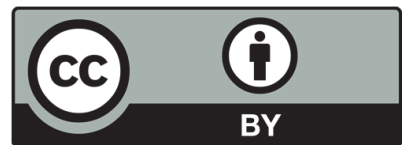

(C) 2017 by the authors; licensee Growing Science, Canada. This is an open access article distributed under the terms and conditions of the Creative Commons Attribution (CC-BY) license (http://creativecommons.org/licenses/by/4.0/). 